\title{
Optimization of Sesame Oil Extraction Process Conditions
}

\author{
Abubakr Elkhaleefa1, Ihab Shigidi1,2 \\ ${ }^{1}$ Department of Chemical Engineering, King Khalid University, Abha, Kingdom of Saudi Arabia \\ ${ }^{2}$ Department of Chemical Engineering, Al-Neelain University, Khartoum, Sudan \\ Email: etaha@kku.edu.sa
}

Received 31 March 2015; accepted 27 June 2015; published 30 June 2015

Copyright (C) 2015 by authors and Scientific Research Publishing Inc.

This work is licensed under the Creative Commons Attribution International License (CC BY). http://creativecommons.org/licenses/by/4.0/

(c) (i) Open Access

\begin{abstract}
In this study, the optimum operating conditions for sesame oil extraction were studied. N-hexane was used as a solvent. Different variables were investigated; sesame seeds particle sizes, ratio of solvent to seeds mass, contact time, stirring effect, roasting impact and extraction temperatures. Results obtained showed that higher rates of extraction were obtained when roasting sesame seed to $150^{\circ} \mathrm{C}$. The ratio of solvent to seeds found to be 6:1 gave higher extraction. Moreover, stirring speed was tested and had been optimized to $600 \mathrm{rpm}$. Finally, the extraction under heating was studied and results showed that increasing operating temperature to more than $40^{\circ} \mathrm{C}$ did not increase extraction efficiency.
\end{abstract}

\section{Keywords}

Solvent Extraction, Sesame Oil, Extraction Variables, Process Optimization

\section{Introduction}

Sesame (Sesamum indicum L.) is cultivated in several countries such as India, Sudan, China and Burma which are considered as the major producers (60\% of its total world production) [1]. Sesame seeds have been used as health food for disease prevention in Asian countries for several thousand years. The literature reports indicate many health benefits associated with the consumption of sesame seeds; for example, they significantly increase plasma $\gamma$-tocopherol and enhance vitamin E activity, which are believed to prevent human aging-related diseases such as cancer and heart disease. Studies have also shown that including sesame in the diet can improve antioxidant capacity [2].

Sesame seed has higher oil content (around 50\%) than most of the known oilseeds. Sesame oil is generally regarded as high-priced and high-quality oil. It is one of the most stable edible oil despite its high degree of un- 
saturation [3]. Sesame oil is rich in monounsaturated and polyunsaturated fatty acids. [2] The most abundant fatty acids in sesame oil were oleic, linoleic, palmitic, and stearic acids, which together comprised about $96 \%$ of the total fatty acids.

Extraction of sesame oil has developed significantly over the years; [4] stated that the mechanical method was an early means of separation which was physical pressure to "squeeze the oil out". The most energy efficient, practical embodiment of that method is the modern screw press. More than half of the oil is easily removed in this way, but perhaps $7 \%$ or $8 \%$ residual oil is left in the cake solid. The process uses considerable horsepower and requires more maintenance, in addition it also requires more machines setups for higher capacity.

In a nutshell, such techniques are no longer prevailing currently due to the higher cake oil content. Solvent extraction, providing higher yields-98\% - 99\% is nowadays the dominant technique applied in most extraction processes. Solvent extraction becomes the commonly used commercial technique to recover oil from oilseeds, presently n-hexane is the preferred solvent throughout the world due to its extraction efficiency and ease of availability [5]. In comparison, solvent extraction with hexane (the primary solvent used worldwide) will remove all but about $0.5 \%$ of residual oil, use less horsepower and require less maintenance. Hence, it is relatively efficient and reliable. In this study, optimization of n-hexane extraction is defined by studying the parameters which affect the process.

\section{Extraction Stages}

The solvent extraction process is not a straight forward application as many processes precede the addition of solvent. The overall process is summarized in the process description, each stage addresses particular parameter, Figure 1.

The weighted sesame white seeds are first sieved to ensure maintaining particularly specified particle size, this is very important to ease the crushing process, hence obtaining uniformly particle sizes. Seeds are then washed to remove any adhering particulates that may be deposited during harvesting that may contaminate the final product. The seeds are then dried before being roasted.

[6] studied the impact of roasting oily seeds and concluded that antioxidant capacity of the roasted seeds and oxidative stability of the extracted oil could be greater than that of the unroasted counterpart. These improvements are attributed to the formation of Maillard reaction products, inactivation of oil degrading enzymes and facilitation of phytochemical extraction as a result of roasting.

The seeds were roasted at different temperatures and durations, [7]; are then crushed to increase the active surface, thus improve the extraction process. [8] examined the impact of sesame particle size on oil extraction and concluded that The extraction yield increased as the particle size decreased depending on decreasing intraparticle diffusion resistance. The particle size from $45 \%$ of the maximum extraction yield obtained was about $300-600 \mu \mathrm{m}$.

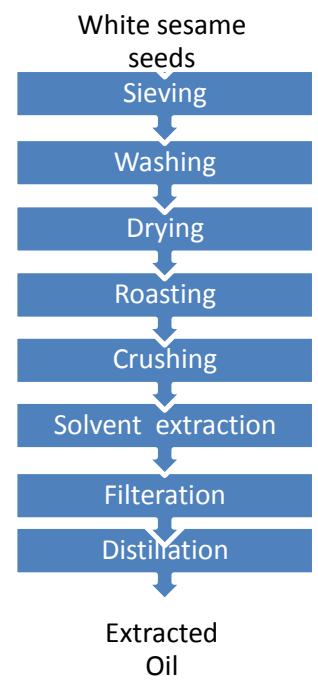

Figure 1. Extraction process description. 
The solvent extraction is the key point-operation. Extraction takes place due to the affinity of solvent towards oil. The affinity is mainly chemically based. Various researchers studied the impact of different solvents on sesame oil extraction, [9] used n-hexane, cyclohexane, benzene, mixture of n-hexane/chloroform (2:1, v/v), chloroform, acetic ether, butanol and acetone, on the other hand [1] used hexane and [10] used compressed popane and supercritical carbon dioxide. Majority of researchers found that n-hexane yields higher extraction percentages making it the optimum solvent.

\section{Experimental Work}

\subsection{Samples Preparation}

Freshly season white sesame seeds were purchased from the local market at Abha city-Saudi Arabia. Particle impurities such as dust, sands, stones, spoiled seeds, small weed seeds and other extra materials were separated by mechanical sieves [11], then washed with water for further cleaning and left to dry at room temperature for 48 hours.

\subsection{Materials and Equipment}

Sesame seeds, n-hexane, sieves, coffee mill, oven, hot plate with magnetic stirrer, Buchner filter, laboratory atmospheric distillation apparatus.

\subsection{Extraction Process Variables}

In this research, various operating parameters that the researchers believe play an important role in extraction were investigated, that included particle size, ratio of solvent to sesame seeds mass, contact time between solvent and sesame seeds, stirring time, roasting temperature effect as well as heating. Conditions of each parameter are presented as follows:

\subsubsection{Particles Size}

Five samples were taken with different average particle size $(2,1.5,1,0.8,0.5 \mathrm{~mm})$ to investigate the optimum sizes that yields higher oil extraction.

\subsubsection{Solid to Solvent Mass Ratio}

10 samples have been prepared with different ratios of sesame seed mass to solvent mass $(1: 1,1: 2,1: 3,1: 4,1: 5$, $1: 6,1: 7,1: 8)$. Samples were kept for 24 hours before being filtered to remove any depositions that may occur. The extracted oil was then separated from the hexane using distillation.

\subsubsection{Contact-Time}

6 samples with the defined optimum ratio determined in section (3.3.2) were taken and kept for different contact periods so as to determine the optimum contact time.

\subsubsection{Stirring Impact}

The effect of different stirring speeds on extraction efficiency have been studied by taking 3 samples with the optimum ratio of seed mass/ solvent mass and kept for the optimum contact time defined in section (3.3.3).

\subsubsection{Seeds' Roasting Affect}

The effect of roasting on the oil extraction yield has been studied by heating the seeds to different temperatures $\left(100^{\circ} \mathrm{C}, 120^{\circ} \mathrm{C}, 140^{\circ} \mathrm{C}, 160^{\circ} \mathrm{C}, 180^{\circ} \mathrm{C}\right.$ and $\left.200^{\circ} \mathrm{C}\right)$ for different durations $(1,2$ and 3 consecutive hours).

\subsubsection{Heating}

The samples were subjected to heating at different temperatures $\left(25^{\circ} \mathrm{C}, 30^{\circ} \mathrm{C}, 35^{\circ} \mathrm{C}, 40^{\circ} \mathrm{C}, 45^{\circ} \mathrm{C}, 50^{\circ} \mathrm{C}\right)$ during contact periods to study the impact of increasing temperature on extraction efficiency.

\section{Results and Discussion}

Firstly; the effect of seeds crushing (particles size) was studied. Figure 2 shows an inversely proportional rela- 
tion between increasing particle size and the amount of oil extracted which is in total agreement with the literature, the optimum extraction value was obtained at $1 \mathrm{~mm}$ where of $33.5 \%$ percent of oil was extracted.

The mass ratio of n-hexane: seeds were then studied. Investigations examined different ratios, from 1:1 up to 8:1. Results showed maximum extraction yield of $37 \%$ oil when applying a ratio of $6: 1$. Further increase of solvent amount had no impact of extracting further oil percentage as presented in Figure 3.

The impact of the residence time between the sesame seeds and n-hexane is examined and presented in Figure 4, it is clear that the more time seeds are given in contact with the solvent the higher the extraction yields percentage, this is true for 24 hours, afterwards no more extraction had been noticed.

The effect of stirring speed on the extracted oil yield was examined and resulted in improving the efficiency of the process. Various speeds were tested, 100, 250, 350, 700, 950 and $1100 \mathrm{rpm}$. The overall result showed proportionality between the extraction and stirring speed. Higher extraction percentage was obtained at $350 \mathrm{rpm}$. Increasing stirrer speed had showed no positive extraction rates, Figure 5.

From the literature the effect of roasting on sesame oil extraction has been presented by number of researchers, in this work the optimum temperature of roasting has been defined by testing the extracted oil yields of seeds roasted under different temperatures from $100^{\circ} \mathrm{C}$ to $200^{\circ} \mathrm{C}$ with $20^{\circ} \mathrm{C}$ increment. The extraction was also monitored for also monitored for consecutive 3 hours and the results for each hour were recorded. Figure 6 shows that roasting seeds for $150^{\circ} \mathrm{C}$ have yielded $42.5 \%$ extraction after only 1 hour, thus increasing roasting temperature did not have any impact on improving process efficiency.

Finally, the extraction process was studied under heating. The seeds were roasted to $150^{\circ} \mathrm{C}$ and added to the n-hexane with the optimized ratio defined earlier (6:1) and under the pre-defined contact and stirring speed. The mixture was left under room temperature where other samples were heated to up to $55^{\circ} \mathrm{C}$ with an increasing increment of $5^{\circ} \mathrm{C}$. The results, Figure 7 showed that maximum extraction of $42.5 \%$ was achieved at only $40^{\circ} \mathrm{C}$ and that increasing temperature is merely an operational cost and has no impact on extraction yield percentages.

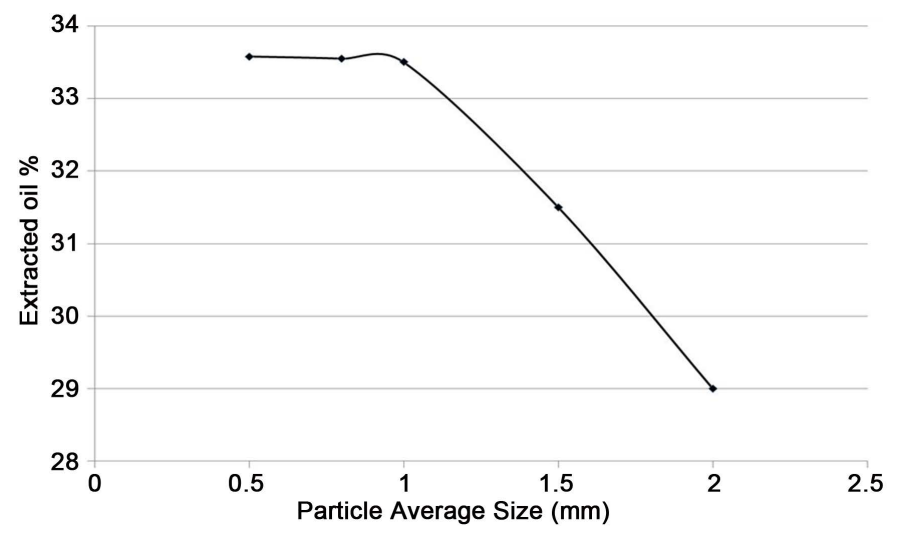

Figure 2. Particle size optimization.

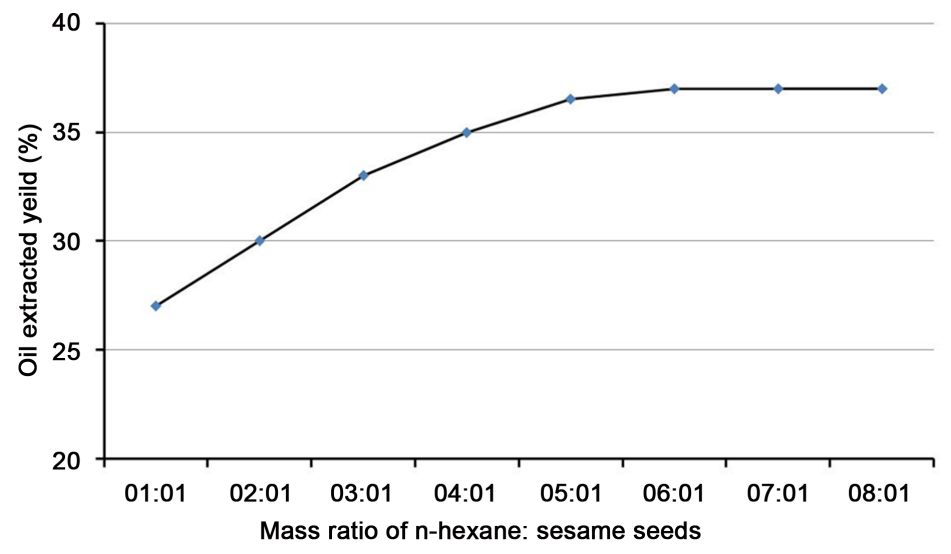

Figure 3. Hexane/seed ratio optimization. 


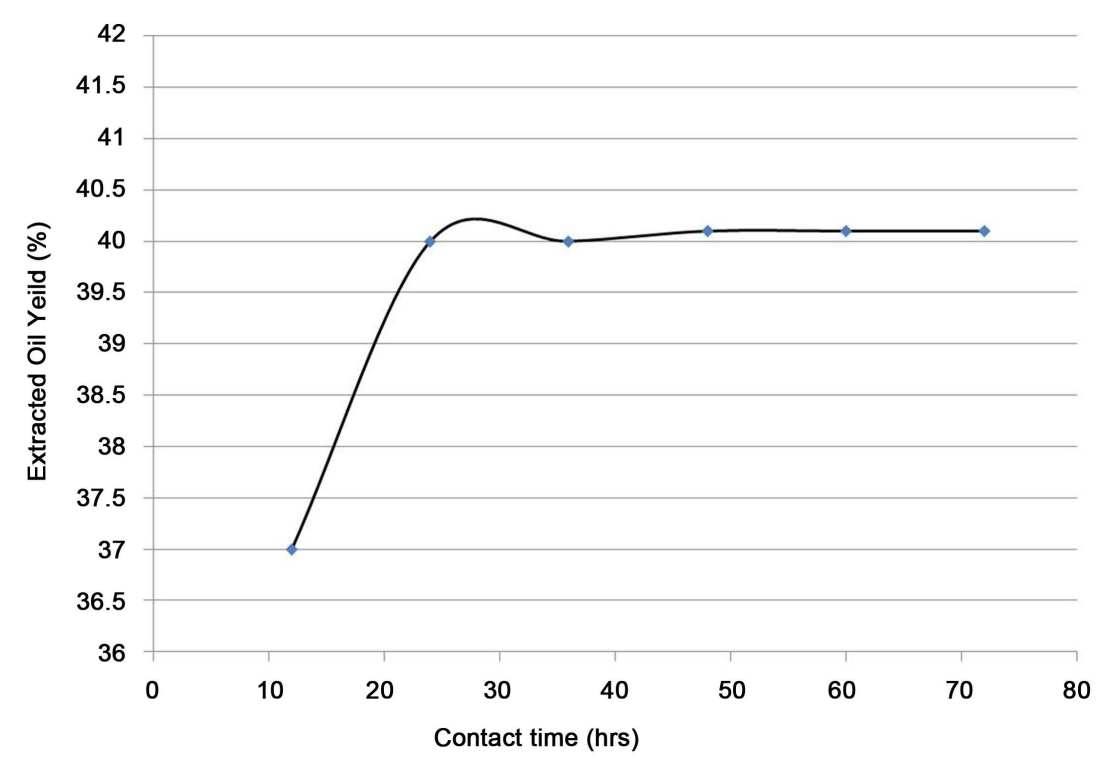

Figure 4. Contact time optimization.

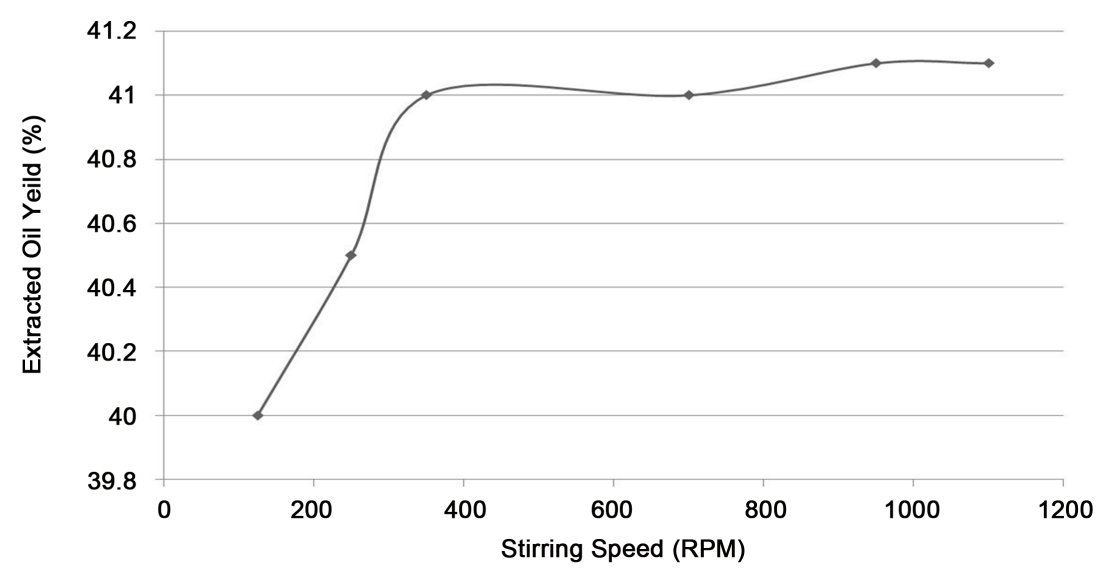

Figure 5. Effect of stirring speed on extracted oil yields \%.

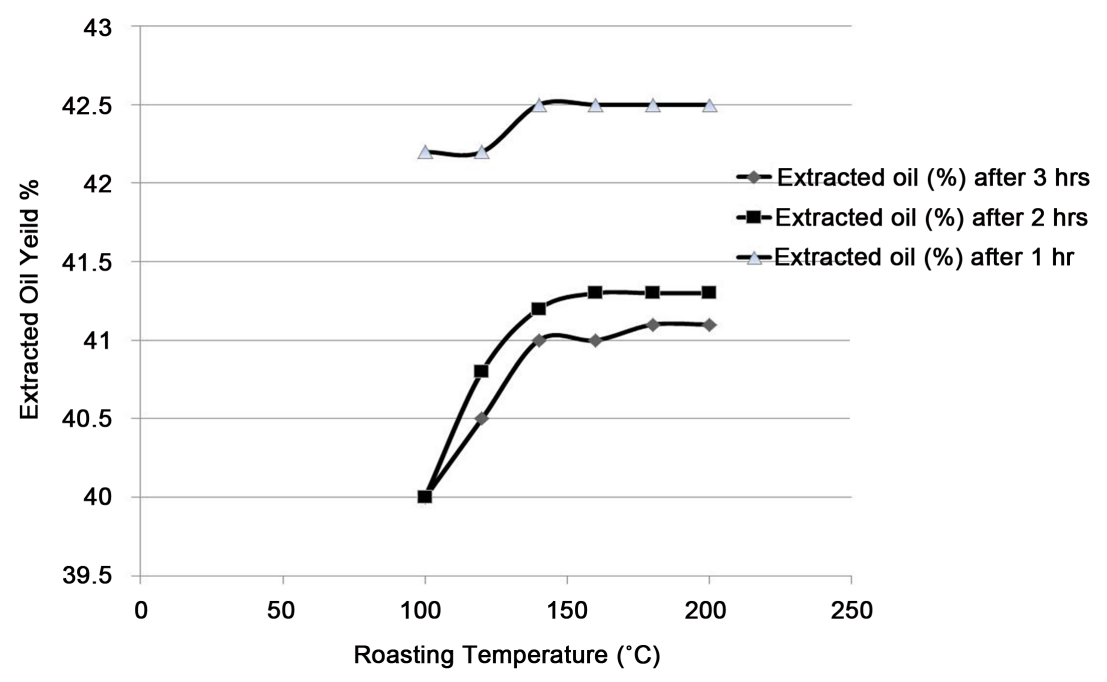

Figure 6. Effect of sesame seeds roasting. 


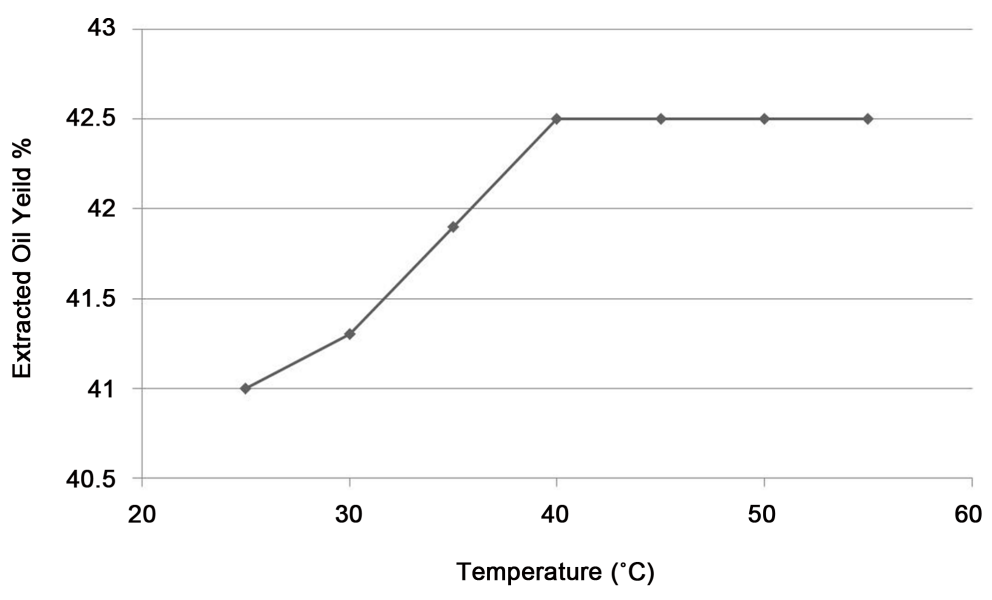

Figure 7. Effect of heating on extraction yield percentage.

\section{Conclusion}

The optimum conditions for sesame oil extraction by n-hexane have been studied and the results presented show that sesame seeds crushing to an average size between $(8-1 \mathrm{~mm})$ yield higher extraction rates. The ratios of solvent to seeds are also tested and the results conclude that with the increasing this ratio over 6:1, hexane to sesame seeds will not result in increasing extraction values. Moreover, the residence time between the n-hexane and the seeds is investigated and the optimum contact time is found to be 24 hours. When looking at the impact of stirring on extraction yields, $700 \mathrm{rpm}$ result in higher values in comparison to other tested speeds. The extraction temperature is also found to be $40^{\circ} \mathrm{C}$ which gives higher extraction rates.

\section{References}

[1] Elleuch, M., Besbes, S. Roiseux, O., Blecker, C. and Attia, H. (2007) Quality Characteristics of Sesame Seeds and ByProducts. Food Chemistry, 103, 641-650. http://dx.doi.org/10.1016/j.foodchem.2006.09.008

[2] Elleuch, M., et al. (2011) Sesame (Sesamum indicum L.) Seeds in Food, Nutrition and Health. Nuts \& Seeds in Health and Disease Prevention, 1029-1036.

[3] Hwang, L.S. (2005) Sesame Oil. Bailey’s Industrial Oil and Fat Products. http://dx.doi.org/10.1002/047167849x.bio031

[4] Primer, A.L. The AOCS Lipid Library. Population (bn) [Cited 1 2.1]; 3.02-6.83.

[5] Saxena, D.K., Sharma, S. and Sambi, S. (2011) Comparative Extraction of Cottonseed Oil by n-Hexane and Ethanol. Journal of Engineering \& Applied Sciences, 6, 84.

[6] Durmaz, G. and Gökmen, V. (2010) Impacts of Roasting Oily Seeds and Nuts on their Extracted Oils. Lipid Technology, 22, 179-182. http://dx.doi.org/10.1002/lite.201000042

[7] Lee, S.W., Jeung, M.K., Park, M.H., Lee, S.Y. and Lee, J.H. (2010) Effects of Roasting Conditions of Sesame Seeds on the Oxidative Stability of Pressed Oil during Thermal Oxidation. Food Chemistry, 118, 681-685. http://dx.doi.org/10.1016/j.foodchem.2009.05.040

[8] Döker, O., Salgin, U., Yildiz, N., Aydoğmuş, M. and Çalimli, A. (2010) Extraction of Sesame Seed Oil Using Supercritical $\mathrm{CO}_{2}$ and Mathematical Modeling. Journal of Food Engineering, 97, 360-366. http://dx.doi.org/10.1016/j.jfoodeng.2009.10.030

[9] Zhou, J.-C., Feng, D.-W. and Zheng, G.-S. (2010) Extraction of Sesamin from Sesame Oil Using Macroporous Resin. Journal of food engineering, 100, 289-293. http://dx.doi.org/10.1016/j.jfoodeng.2010.04.011

[10] Corso, M.P., Fagundes-Klen, M.R., Silva, E.A., Filho, L.C., Santos, J.N., Freitas, L.S. and Dariva, C. (2010) Extraction of Sesame Seed (Sesamun indicum L.) Oil Using Compressed Propane and supercritical Carbon Dioxide. The Journal of Supercritical Fluids, 52, 56-61. http://dx.doi.org/10.1016/j.supflu.2009.11.012

[11] Rostami, M., Farzaneh, V., Boujmehrani, A., Mohammadi, M. and Bakhshabadi, H. (2014) Optimizing the Extraction Process of Sesame Seed'S Oil Using Response Surface Method on the Industrial Scale. Industrial Crops and Products, 58, 160-165. http://dx.doi.org/10.1016/j.indcrop.2014.04.015 